\title{
Teaching College English Grammar in a Cognitive Task-Based Approach
}

\author{
XU Jing \\ Shanghai Institute of Technology, Shanghai, China
}

\begin{abstract}
Teaching College English in a cognitive task-based approach is actually a way to incorporate the grammar teaching within the well-sequenced activities. In this approach, language teachers draw learners' attention to the grammatical structures and try to be explicit about the relation between the form and the function either to confirm or to correct learners' hypotheses and develop their cognitive form-meaning mapping. The tasks should be designed to allow the structure to happen incidentally rather than give an overt explanation of rules. By the individualized mapping of meaning to the forms in the real meaningful context, the learners' initiatives in learning grammar would be greatly triggered.
\end{abstract}

Keywords: grammar fatigue, form-meaning mapping, a cognitive task-based approach

\section{Introduction}

For a long time, the pendulum of the approaches to teaching College English Grammar (CEG) in China swings more or less on a continuum between the explicit and implicit extremes. The earliest approach, the grammar translation approach, is quite on the explicit side. Language teachers are expected to introduce the grammar rules with the translation and vocabulary study as the main activities while the students' learning is characterized by the rote memorization of the rules and the mechanic practice through the drills outside the context. Meanwhile the similarly comparatively earlier approaches the direct method and audiolingualism influenced by the behaviorist psychology towards the implicit approach hold that the grammar of the second language can be acquired in the same process as the students' acquisition of their native languages (Rodriguez, 2009). The two methods, however, failed to be integrated into Chinese CEG teaching probably resulting from the fact that English is the foreign language instead of the second language in China, which may be absent from the substantial language input leading to the internalization of grammar rules. In 1990s, the communicative approach sticks to the implicit nature but manifests a totally different angle shifting the focus from the structure to the communication which emphasizes on the meaningful interaction of the activities. It argues that communication is the ultimate goal of language teaching rather than grammar which is only an instrument to serve the purpose of communication. Under such a communicative framework, grammar is not explicitly taught as it is claimed that the accuracy would be acquired through the authentic communication.

Studies on the merits and demerits of the above approaches all suggest the disintegration of form and meaning. More recently, the cognitive grammar which contends linguistic structure is associated with a particular way of conceptualizing a given situation (Lee, 2001, pp. 1-7), trying to include the forms in the

XU Jing, associate professor, M.A., School of Foreign Languages, Shanghai Institute of Technology. 
meaningful conceptualization exerts a strong influence on the language teachers. Therefore in this paper, the role of CEG teaching in China is examined and a cognitive task-based approach to teach CEG is suggested to focus the form in the communicative activities.

\section{The Role of CEG Teaching in China}

It is always questionable about the role of grammar in modern English teaching. However, Canale and Swain (as cited in Leech \& Svartvik, 1994, p. 3) state that communicative competence consists of grammatical competence, sociolinguistic competence, and communicative strategies. There is no theoretical or empirical evidence which shows that grammatical competence is any more or less crucial to successful communication than sociolinguistic competence or communication strategies. Therefore, grammar is important but cannot account for all. Chinese college students all have a systematic command of English after at least nine years' school English. Yet their proficiency in actually using the language is disappointing maybe due to "grammar fatigue" (Leech \& Svartvik, 1994, p. 3) caused by the traditional grammar teaching approach. All the time through the learning process, they have been offered those grammatical drills and exercises by language teachers to ensure they could get the right forms or structures but without any purpose. They do not know where, how, and when to apply their grammar in a simulated context or in the real world. In other words, they do not have knowledge about functions of grammatical forms.

Emphasis on the use of language, however, does not mean that language teachers should abandon grammar instruction all together and fashion a more free-form communicative class where the explicit instruction in grammar is simply absent and the learners tend to discover grammatical rules on their own always corrected by enough language input. Provision of fixed rules and principles can add to, confirm, or modify the hypothetical rules which learners discover by themselves (Mohammed, 1993, p. 59). The explicit teaching of grammar at an appropriate time may be a short cut to learning the forms and structures, contributing to the language accuracy especially when the adult learners are concerned. College adult students in China tend to acquire the language more metacongnitively rather than unconsciously and therefore they would learn more effectively when given the clear instruction of the grammatical rules.

Consequently, there have also been a lot of debates in China about the role of CEG teaching. On one side, it is argued that teaching grammar is a component of language teaching. Language teachers should draw learners' attention to the forms or structures of language and give them rules of usage explicitly. On the other side, it is regarded that grammar is not important in a communicative approach to language. Learners are encouraged to communicate both in writing and speaking more and "pick up" grammar naturally. As a result, the reform of College English Teaching has also complied with the above debate and followed the general trend moving from the traditional grammar translation approach to the communicative approach. College English Curricular Syllabus stipulated by Ministry of Higher Education in 2007 directs towards the cultivation of the students' integrative English application competence especially in speaking and listening without reference to the accuracy of language. Meanwhile the reform in CET- 4 and CET- $6^{1}$ cancelled the traditional item of Vocabulary and Structure with the improved ratio of Listening. However, after a decade of the weakening sense in CEG teaching, the decrease in English accuracy of college students is worrying the teachers, which manifests in various aspects like reading comprehension, writing, and translation. The grammatical mistakes in writing

\footnotetext{
${ }^{1}$ College English Test Band 4 and Band 6 are the national standardized tests of English proficiency for all the non-English major students in universities and colleges of China.
} 
are irritating as they should not have happened to a college student who has studied English in class for so many years.

From the grammar fatigue to the decrease in accuracy, there is no deny that both the grammar translation approach and the communicative approach with an exclusive emphasis on either extreme impede the acquisition of grammar and ultimately lead to the difficulty in the overall English learning. On the contrary, the cognitive grammar has subverted the traditional concepts of grammar as the metonymy of structure independent of meaning and instead assimilated meaning and form by individual construals. It contends the conceptual mapping between reality and language is closely related to the experience of the speaker to the reality and thus how the speaker conceptualizes the reality gives rise to the individualized meanings. The cognitive grammar is thus enlightening as it protests against the mechanic memorization of the grammar rules by connecting the form with meaning through individual cognitive metaphorization, which lays an emphasis on the students' initiatives in the meaningful construction while drawing their attention to the forms.

\section{Influence of Cognitive Linguistics}

Language is a tool to reflect the reality but what is rather weird is that different people may have different linguistic expressions as to the same reality. Although Generative grammarians contend that these linguistic expressions are basically the same in terms of the deep structure, Cognitive linguists claim that they are different in meaning, which is related to how different people perceive the same scene. When a particular scene is conceptualized in different ways, hence the different linguistic structures are construed accordingly by the mechanism of "perspective, foregrounding and framing" (Lee, 2001) through metaphorical mapping.

One of the ways to realize the alternative construals is to describe the scene from the different perspectives, but that actually explains how people view the scene from different physical angles or points of view. Consider, for example, the contrast between examples (1) and (2), (3) and (4):

Example (1) I lent the money to John a few days ago.

Example (2) John borrowed money from me a few days ago.

Example (3) There is a garden in front of my house.

Example (4) My house is located behind a garden.

Examples (1) and (2) show the same event is conceptualized either from my point of view in example (1) or John's point of view in example (2). At the same time, Examples (3) and (4) illustrate the exact location of my house from different reference points. Standing at a point right between the garden and the house, there is a garden spreading forward as construed in example (3); while standing in front of the garden facing the house, it is right behind the garden.

Another way leading to different construals is to highlight the different components of the same situation. In other words, when the event is perceived in cognition, some components draw more attention visually or are deliberately put more focus than the other background elements. Here are some examples to further explain the issue.

Example (5) The red balloon appeals to the little baby.

Example (6) The little baby was attracted by the red balloon.

It is interesting examples (5) and (6) themselves show the prominent attention. Example (5) is so construed perhaps to highlight the natural attraction of the red color to the baby while example (6) is directed to the little baby's curiosity. In both encodings, some aspects are made salient while the others are backgrounded. 
The last but not the least way to construe the given scene differently is realized by framing, which more or less deals with the meaning of words. Within the different frames (of background information), words are decoded differently. The concept of frame is multi-dimensional not only because of the cognitive differences but more of a cultural matter. Here are some further illustrations of the point.

Example (7) The proposal was temporarily tabled due to more pressing business.

Example (8) There is a table of contents in the front of a dictionary.

Example (9) The table in the rear were very noisy.

None of the word "table" is a prototypical sense of a wooden piece of furniture for dinner. In example (7), to be "tabled" is to be held back in the frame of negotiation around a table. In example (8), a "table" means a list shaped like a table in the frame of book components. In example (9), the "table" means the people at table in the closest frame to its original sense. Even for its prototypical sense, a "table" would be configured to different images, with a rectangular one in American but a round one in Chinese culture.

To conclude, we produce different linguistic structures because our cognitions process the same scene in disparate ways. That is, we construe the reality from different perspectives, within distinct frames and with various focuses. Therefore, the learning of forms takes place in a meaningful conceptualization of the reality. Teaching CEG in a cognitive task-based approach will promote learners' actual use of language while maintaining accuracy.

\section{A Cognitive Task-Based Approach to CEG Teaching}

The meaningful communicative tasks can effectively be used to facilitate learners' cognitive development of grammatical knowledge through hypothesis, to add to, modify, or confirm these hypotheses by language teachers, and to inspire them to use the grammar consciously and meaningfully in their communications.

Nunan (1990) has a model for designing tasks involving six factors: Goal, Input, Activity, Teacher's Role, Learners' Role, and Settings (p. 48). Nunan (1999) also says a task should involve three principles: authenticity principles, form and function principle, and task dependency principle (pp. 26-31). Based on Nunan's model and principles, the following points are suggested as for how to design a successful grammatical task by involving the individual conceptualization.

First and foremost, learners should be supplied with enough authentic materials to discover the form and identify the meaning of the form while language teachers' explicit grammar instruction will help learners to internalize the input correctly. According to the language acquisition model put forward by Lee and VanPatten (1995), the brain uses intake rather than raw input data to create a linguistic system (p. 94). Therefore, language teachers should design tasks to facilitate learners to notice the grammatical features and enable them to identify the different meanings realized by the specific grammatical features, i.e., "to help them carry out a form-function mapping" (Ellis, 1995, pp. 87-95). But unfortunately, not all the learners can notice this form-function mapping or grammar comprehension. They may actually carry out message comprehension, which can take place without learners having to attend to the grammatical form. It is, then, the right time for language teachers to be quite explicit about the grammar feature and its function, which help learners to modify their incorrect hypotheses or confirm their correct hypothesis before these hypotheses are actually being internalized and incorporated into learners' interlanguage system. In addition, by comparing the different forms associated with the same reality, students are greatly involved in mapping the meanings to the structures. 
When it comes to language output developed from input, language teachers should design the task, enabling learners to access a particular form automatically in order to express meaning, i.e., "a closed task" (Loschky \& Vroman, 1993, p. 125). Compared with input, it would be very difficult to design controlled output tasks. If the task is too closed, it would be like drills on grammar practice. In contrast when it is "too communicative", learners would not turn to the grammar form introduced by the previous input. Therefore, it would be much easier and more effective to ensure that there is only one form or one function being focused in a particular grammatical task. Practicing a pattern communicatively often involves using a topic context as stated by Hood (1994, p. 24), which is aimed at the situational and contextualized use of language. Loschky and Vroman (1993, p. 141) argued that communicative structure-based production tasks will be most valuable as "practice" activities to develop the automation of a specified structure stipulated by these situations and contexts. However, learners are also encouraged to construct their own structures by negotiating the respective understandings. Thus innovation in language construction is encouraged by individualized construals.

Last but not the least, in order to make learners resort to the form consciously in a meaningful task, the grammar should be heavily scaffolded as Nunan states in his task dependency principle (1999, pp. 26-31) that each task in a sequence should lead to the next, e.g., "like the rungs of a ladder-each rung gets the learner higher and higher". Teaching grammar is just like a continuum. At one end of this continuum, there is the shaping or more controlled exercises at a word or sentence level, while at the other end of this continuum, there are very communicative activities at a discourse level. Learners cannot be expected to use forms automatically without the previous closed grammatical exercises and language teachers' explicit instruction about the meaning of the form.

\section{Conclusion}

CEG teaching in a cognitive task-based approach is actually a way to incorporate the grammar teaching within the well-sequenced activities. In this approach, language teachers draw learners' attention to the grammatical structures by sufficient input rather than "simply letting the grammar take care of itself" (Loschky, \& Vroman, 1993, p. 156), and try to be explicit about the relation between the form and the function either to confirm or to correct learners' hypotheses and develop their cognitive form-meaning mapping. On the other hand, the task should be designed to allow the structure to happen incidentally rather than give an overt explanation of rules. The structures should be always put back into the right context to have a meaning so that learners can be prepared for the real world. By the individualized mapping of meaning to the forms, the learners' initiatives in learning grammar would be greatly triggered.

\section{References}

Ellis, R. (1995). Interpretation tasks for grammar teaching. TESOL Quarterly, 29(1), 88-105.

Hood, P. (1994). Communicative grammar: A practical problem-solving approach. Language Learning Journal, 9(1), 28-31.

Lee, D. (2001). Cognitive linguistics: An introduction. Oxford: Oxford University Press.

Lee, J., \& VanPatten, B. (1995). Making communicative language teaching happen (pp. 89-133). USA: McGraw-Mill, Inc..

Leech, G., \& Svartvik, J. (1994). A communicative grammar of English. New York: Addison Wesley Longman Inc..

Loschky, L., \& Vroman, R. (1993). Grammar and task-based methodology. In G. Crookes and S. Gass (Eds.), Tasks and language learning. Adelaide: Multilingual Matters Ltd..

Mohammed, M. (1993). Towards a leaner-centered technique of teaching grammar. Language Learning Journal, 7(3), 59-63.

Nunan, D. (1990). Designing tasks for the communicative class. Cambridge: Cambridge University Press.

Nunan, D. (1999). Second language teaching and learning. Boston: Heinle \& Heinle. 
Rodriguez, A. G. (2009). Teaching grammar to adult English language learners: Focus on form. CAELA Network Brief, 1-4.

Tomlin, S. (1994). Functional grammars, pedagogical grammars, and communicative language teaching. In T. Odlin (Ed.), Perspectives on pedagogical grammar. Cambridge: Cambridge University Press. 